\title{
Allocating Water Rights in New Zealand: The Role of Tradable Permits
}

\author{
Susan Begg
}

$\mathbf{M}$

AJOR conflicts exist in New Zealand between using water for consumption or electricity generation, and protecting in-stream water to produce conservation, cultural and recreational outputs. Under the Resource Management Act 1991 (RMA), in-stream values are generally protected by councils, ${ }^{1}$ which establish minimum flows through regulatory means, though the government may impose more extensive restrictions on a water body or waterway by means of a water conservation order. But information about the value of water in competing uses is generally very limited. The difficulty of measuring the demand for conservation, recreational and cultural outputs makes it hard for users or councils to choose optimally between conservation and other uses of water.

If individuals and groups could obtain permits to leave water in-stream, then conservation, recreation and cultural outputs could be privately provided, increasing the quality of water for all. Extending the tradability of water permits to in-stream uses could help resolve the conflict between conservation and other uses of water.

\section{Institutional Background}

Tradable water permits are possible in New Zealand under the RMA. Responsibility for managing fresh water rests with the twelve regional councils and four unitary authorities guided by broad principles set out in the RMA. The RMA governs the abstraction of water and disposal of effluent, and sets out restrictions on the use of the beds of lakes and rivers, water use and the discharge of contaminants. These restrictions are binding unless they are waived by a rule in a regional plan, or a council has issued a resource consent (a 'permit'). A permit to extract and discharge water from rivers can run for no more than 35 years. If it is not exercised, it expires after two years or such shorter or longer period as is expressly provided for in the permit.

In setting rules for water use and discharges into water, councils are required to meet standards set out in the RMA. The RMA specifies minimum standards for water quality, allowing councils to specify higher standards if they wish. Standards may be lower if consistent with the Act: if, for example, there are mitigating benefits. Water standards are generally descriptive rather than quantitative.

\footnotetext{
${ }^{1}$ Regional councils and unitary authorities are responsible for resource management and related functions. Here, the term 'council' is used to cover both types of authority.
} 
The RMA does not allow the transfer of discharge permits from site to site. But it does allow transfer of water permits either through the consent process or by councils specifying conditions for transfer in a regional plan. Although water permits can be transferred through the consent process, a market for water permits is unlikely to develop without councils specifying the conditions for transfer in a regional plan. Regional plans have the potential to reflect the specific circumstances of a catchment or groundwater system that are relevant in developing a transferable permits regime and potentially make it easier for trading to occur.

Several councils are investigating transferable water-permit regimes; and one limited regime is currently in operation in the Oroua River catchment. In the proposed and existing regimes, permits to abstract water are transferable within constraints defined in the plans. In all cases, councils continue to set minimum instream flows through administrative means rather than integrating in-stream use into the transferable water permits regime.

\section{Integrating In-Stream Values into a Tradable Water Permit Regime}

Conservation, cultural and recreational outputs are produced by leaving water instream. If permits to leave water in-stream could be obtained, then conservation, cultural and recreational in-stream outputs could be provided by private groups which obtained permits. Under the current regime, this effect could be achieved by groups obtaining permits to abstract water, and then not exercising them. ${ }^{2}$

The impact of not exercising a permit would depend on how permits were defined. If defined as a proportion of in-flows, permits held by conservation groups (and not used to abstract water) would increase in-stream flows in all circumstances. If defined as different priority volume entitlements, the non-exercise of permits that increased in-stream flows would increase the security of flows and allow other abstracters to appropriate the allocation left in-stream unless special provisions were made for conservation users. Under current arrangements, a plan change would be required to increase or decrease minimum flows. Since a plan change is a timeconsuming and inflexible process, procedures would need to be established to facilitate protection of conservation values.

If individuals were able to obtain a permit for water abstraction and could choose not to exercise it, then, under a tradable permit regime, conservation interests would be able to compete with abstractive users for permits. Conservation interests could purchase permits from abstractive users and by choosing not to abstract water could increase in-stream flows. Allowing the trading of permits for both in-stream and abstractive use would help ensure that water was allocated to the use

\footnotetext{
2 The RMA provides that a resource consent lapses after two years, or after such shorter or longer period as is expressly provided in the consent, unless it is exercised. Thus, it appears that if a council specifies a period significantly in excess of two years within which permits must be exercised, private conservation groups could obtain water permits and not exercise them. However, the development of case law suggests that permits cannot be issued for non-active uses. Thus, an amendment of the RMA may be necessary before in-stream uses could be incorporated into a transferable permits regime.
} 
creating the most value. Conservation groups could express their preferences for in-stream water directly through buying and selling permits rather than being forced to lobby councils for protection of in-stream amenities.

The 'public good' nature of some of the cultural, recreational and conservation outputs that are created by leaving water in-stream means that private interests may underprovide in-stream flows, ${ }^{3}$ since it may be difficult to exclude non-payers from enjoying the cultural, recreational and conservation outputs, and the enjoyment of these outputs by one person would generally not reduce the scope for use by others. To overcome underprovision, the councils could provide the outputs themselves by setting minimum in-stream flows or holding permits for minimum flows. If the councils establish minimum in-stream flows by regulatory means, conservation and other groups could still increase in-stream flows above the minimum set by the councils by buying permits; but they could not reduce flows below the minimum.

Alternatively, councils could allocate permits for in-stream flows to private groups, or councils (or central government) could subsidise private groups to purchase permits for in-stream flows. The agents qualifying for funding could include conservation groups, research and philanthropic foundations, Maori organisations, and possibly commercial entities such as tourism operators.

If private conservation interests or a council agency held permits for current minimum flows, a possible option would be to allow them to trade the permits to maximise in-stream amenities across rivers. For example, in areas of relatively low environmental significance, permit holders could sell all water permits for in-stream flows, potentially reducing minimum flows to zero. The private groups or council could use the funds thus obtained to buy water permits in other rivers with more valuable environmental or other amenities. They could maximise conservation outputs by purchasing permits in high conservation areas where competing uses of water were limited rather than high conservation areas where the value of water to other users was also high. Allowing the permit holders to trade entitlements would help ensure that they maximised the overall conservation value of in-stream flows and that water was allocated to its most valuable use.

This trade-off approach was adopted in 1990 by the Department of Conservation and Electricity Corporation of New Zealand in the Waitaki catchment under the current regime. Electricity Corporation of New Zealand enhanced the environment in the Ahuriri River, which provides black stilt habitat, in exchange for having no minimum flow on the Pukaki River. ${ }^{4}$ Mandatory minimum in-stream flows would preclude such mutually preferred outcomes.

Environmental standards would be determined by the level of funding provided privately and by councils and central government. But it is difficult to assess the appropriate level of such government funding, taking into account the existing provision of national parks and other government-sponsored environmental amenities,

\footnotetext{
${ }^{3}$ Note that the alternative of political allocation may equally result in too little (or too much) conservation from an efficiency perspective.

${ }^{4}$ Russell Howie, personal communication, February 1995.
} 
as well as private collective provision and the incidental provision of conservation values by other water users (such as those involved in the tourism industry). As well, the difficulties of assessing the value of the conservation, recreational and cultural outputs provided would make it hard to ensure that private groups were accountable for any council or government funding they received. Matching private funds with a council or government subsidy could increase the accountability of conservation and other groups, since organisations would receive private and government funding only to the extent that they met the needs of their constituents better than competing organisations.

However, groups relying on council or government funding run the risk that the council or government might force them to compromise some of their principles to obtain funding. Unexpected changes to funding arrangements may adversely affect long-term management of resources. In addition, special interest groups will not necessarily reflect all the public interests in water but may reflect their own particular preferences and uses. Councils concerned about this could participate in the market, although they may themselves reflect the values of particular interest groups.

A market approach to water allocation is sometimes opposed because of objections to, or measurement problems with, putting a monetary value on water used for recreation, scenic appreciation, cultural sustenance or conservation. But since a measurable opportunity cost to water left in-stream exists in the form of its alternative value in abstractive uses, a monetary value for water left in-stream is at least implied.

In deciding whether to leave water in-stream under current arrangements, the councils need to trade-off preferences for in-stream outputs against the opportunity value of water in alternative uses. Determining the value of water left in-stream to those who benefit is problematic. Under an administrative approach, the beneficiaries have incentives to overstate their preferences for in-stream water. Under the market arrangements discussed above, these groups can directly express their preferences by buying or selling permits. This ability to trade provides incentives for these groups to make explicit trade-offs between in-stream and development values. Trading would generate information about the value of water in non-conservation uses and therefore about the opportunity cost of water left in-stream. Note that a tradable regime does not prevent lobbying of government for additional funding of conservation outputs.

\section{Integrating Water Quality Considerations}

Water can carry effluent from industrial and farming activities. This use competes with other uses of in-stream water and abstractive use. Abstraction of water reduces the ability of surface water to assimilate waste. Poor water quality is inconsistent with some conservation, recreation and cultural uses of water. In establishing water quality standards, the value of water for in-stream or abstractive uses as opposed to carrying effluent needs to be considered. If water standards are too high, industries discharging to a waterway may invest too much in pollution control, output may be 
constrained and some abstractive uses may be prevented. If standards are too low, environmental damage may result and cultural and recreational uses may suffer.

Currently, councils set water quality standards by administrative means and use discharge permits to control water quality. This requires councils to determine the assimilative capacity of a waterway and issue discharge permits up to this limit. ${ }^{5}$

The RMA does not allow the transfer of discharge permits from site to site. Although a number of difficulties are likely to limit the scope for a tradable discharge permits regime (Begg et al., 1995:48-9), there seems no good reason to block the development of such a mechanism. Experimentation will not be possible as long as a tradable discharge permit regime is not allowed in New Zealand.

Incorporating effluent disposal into a tradable water permits regime may facilitate the trade-off between effluent disposal and other water uses. One option would be for councils to define the amount of water necessary to assimilate a certain quantity of pollutant or combination of pollutants, and then require dischargers to purchase water permits to leave in-stream the quantity of water needed to carry the pollutants. Polluters would have to buy water permits in competition with other users (both abstracters and other in-stream users), allowing a direct comparison of the values of different uses. Others who had in-stream permits for conservation or recreation uses could on-sell some of the assimilative capacity of their water.

Nevertheless, an integrated approach does not avoid the need for councils to define administratively the quantity of water required to assimilate pollutants. By so doing, councils define the lowest acceptable quality of a water body. If all permits for in-stream water were used to assimilate pollutants, the lowest acceptable quality of water would prevail. If permit-holders left water in-stream for reasons other than efluent disposal, water quality would be higher than the minimum. Thus, the overall quality of water would, at least in part, be determined by competition for water permits for different uses.

However, the proposed approach would not handle the discharges from run-off that are responsible for many quality problems. A further difficulty would be that the quantity of water needed for assimilation would differ for each pollutant and the use of water to assimilate one pollutant would not preclude its use for other pollutants.

\section{Reference}

Begg, S., T. Cowen \& B. Wilkinson (1995), Reform of the Water Industry, paper prepared by CS First Boston NZ Limited for the New Zealand Business Roundtable, Wellington.

\footnotetext{
${ }^{5}$ Councils generally do not require permits for discharges such as animal waste, pesticide, and sediment in run-off because of the administrative costs. Instead they generally handle such discharges by administrative tools such as restricting land-based activities, siting potentially polluting industries away from waterways, ensuring they operate to minimise pollution, and encouraging the planting of niparian strips.
} 